\title{
Attachment-Based Family Therapy: A Review of the Empirical Support
}

GUY DIAMOND* JODY RUSSON SUZANNE LEVY

Attachment-based family therapy (ABFT) is an empirically supported treatment designed to capitalize on the innate, biological desire for meaningful and secure relationships. The therapy is grounded in attachment theory and provides an interpersonal, process-oriented, trauma-focused approach to treating adolescent depression, suicidality, and trauma. Although a process-oriented therapy, ABFT offers a clear structure and road map to help therapists quickly address attachment ruptures that lie at the core of family conflict. Several clinical trials and process studies have demonstrated empirical support for the model and its proposed mechanism of change. This article provides an overview of the clinical model and the existing empirical support for ABFT.

Keywords: Attachment-Based Family Therapy; Adolescents; Depression; Suicidal Ideation; Research

Fam Proc $x: 1-16,2016$

\section{INTRODUCTION}

$\mathrm{T}$ The mechanical-based model of cybernetics and the biological-based model of general systems theory pushed us to look beyond intrapsychic processes for sources of illness and strength. These theories, however, did not provide a clinically meaningful framework for understanding the interpersonal and emotional motivations that drive the quality of family relationships. In contrast, Attachment Theory (Bowlby, 1969) describes how the life-long interactions between individual needs and relational experiences determine the quality of family life and individual development. For Bowlby, what happens in relationships shape one's internal working model or expectations of self and other. These models in turn influence how individuals behave in relationships; a transactional process that continues throughout the life span.

Attachment theory also provides a model for understanding therapeutic change. The theory proposes that psychological growth results from a mixture of improving self-reflection and self-understanding combined with promoting new, more positive, experiences in actual relationships. Given this interactional model of change, many individual and family therapists have turned to attachment theory to describe the therapeutic process (Diamond, Diamond, \& Levy, 2014; Fosha, 2000; Hughes, 2007; Johnson, 2004; Lieberman, 2004; Solomon \& Siegel, 2003; Young, Klosko, \& Weishaar, 2003). In individual therapy, however, the therapist serves as the secure base - the "good parent" who resuscitates the

*Couple and Family Therapy, Drexel University, Philadelphia, PA.

${ }^{\dagger}$ Drexel University College of Nursing and Health Professions, Philadelphia, PA.

Correspondence concerning this article should be addressed to Jody Russon, Drexel University College of Nursing and Health Professions, 3020 Market St. Suite 510, Philadelphia, PA 19104.

E-mail: jmr439@drexel.edu. 
patient's trust in others and confidence in oneself. However, the individual therapist's empathic and consoling statement of "it is not your fault" pales in comparison to the validation a child receives when the parent says, "it was not your fault." In family therapy, the actual family members sit in the room together with the opportunity for each person to better understand and change their role in the family process. Therefore, from an attachment perspective, individual and relational change occurs through the restoration or refurbishing of healthy, trustworthy, reliable, and emotionally sensitive parent-child relationships (Kobak \& Sceery, 1988).

Attachment-based family therapy (ABFT; Diamond et al., 2014) capitalizes on the innate, biological, and existential desire for meaningful and secure relationships. Therefore, we do not start therapy with problem solving or behavioral management. Instead, like emotion-focused couples therapy (Johnson, 2004), we work to uncover what experiences (e.g., abuse) and relational processes (e.g., harsh criticism) have damaged trust in family relationships. We uncover these "traumas" and help the family have an authentic, honest, emotionally engaged, and regulated conversation about these relational disappointments. Topics might include varying degrees of abuse, neglect, abandonment, or life circumstances like divorce, parental depression, or loss. At one level, these conversations help individuals resolve or work through these traumas. At another level, these conversations provide an opportunity for adolescents and parents to practice newly learned relational skills. At a third level, this conversation enacts a corrective attachment experience: children express vulnerable thoughts and feelings and parents remain available, responsive, and emotionally attuned. Engineering these attachment-promoting conversations improves views and expectations of self and others, which, in turn, impacts how family members interact together.

Thus, we developed ABFT to explicitly target the improvement of attachment security as the primary mechanism of change. Still, ABFT is rooted in four family-based clinical traditions. From structural family therapy (Minuchin, 1974; Minuchin \& Fishman, 1981), we rely on the concept of enactment. These in-session, in vivo experiences of change consolidate psychological and interpersonal learning. From multidimensional family therapy (Liddle, 2010), we borrow the framework of using psychological science to inform the selection of treatment targets and our understanding of how to facilitate the therapeutic process. From emotion-focused individual (Greenberg \& Paivio, 2003) and couples therapy (Johnson, 2004), we incorporate a focus on emotions as a key ingredient of therapeutic change. Finally, from contextual therapy (Boszormenyi-Nagy \& Krasner, 2013), we borrow the concept of trust as the basic fabric of family life, without which behavioral and interpersonal problem solving will fail.

Attachment theory, however, provides the primary theoretical and clinical framework of ABFT. Attachment theory posits that when parents are sensitive and available, children grow up with the confidence that parents will support and protect them, while also feeling worthy of being loved and protected. From these trustworthy relationships, children also learn to regulate their emotions. For instance, children use parents to soothe their anxieties and fears, thus learning to down regulate negative affect and to feel comfortable expressing vulnerable emotions. Over time, children begin to internalize these relational expectations as internal working models, setting the foundation for what they will expect from others in future relationships.

The role of secure attachment is no less important in adolescence. Rather than separation and individuation (e.g., Erikson, 1968), the central task of adolescence is to maintain attachment while negotiating autonomy. Adolescents who keep this balance do better in school, have fewer deviant peer relationships, and even have better health outcomes (Allen, Moeller, Rhoades, \& Cherek, 1998; Kobak, Cassidy, Lyons-Ruth, \& Ziv, 2006; Lynch \& Cicchetti, 1991; Rosenstein \& Horowitz, 1996). When adolescents do not have a 
safe and protective parenting environment, they lack this essential developmental context where interpersonal problem-solving and emotion regulation is learned, thus putting them at risk for a number of psychiatric disorders (Cicchetti \& Toth, 1995; Sheeber, Hops, \& Davis, 2001).

\section{ATTACHMENT-BASED FAMILY THERAPY}

Although ABFT is an interpersonal, process-oriented, trauma-focused approach, ABFT offers a clear road map for therapists. The therapy unfolds around five well-defined therapeutic tasks. Task 1, the relational reframe (one session) helps move the family from focusing on the patient's symptoms to focusing on improving the relationship between parent(s) and adolescent. In part, every family therapy model has to sell the idea that the family as a whole is instrumental in helping one member recover from mental illness. In ABFT, we motivate parents and adolescents by asking them to recall how the depression/suicide and/or traumas have created distance between each other. We then amplify that desire for closeness (e.g., attachment and caregiving). Discovering what has damaged trust in the relationship becomes the initial goal of therapy.

Task 2 is the adolescent alliance-building task (two to four sessions). Initially, these sessions focus on getting to know the adolescent's strengths and interests. Then, the therapist helps the adolescent develop an attachment rupture narrative. This conversation explores how the ruptures in attachment security fuel or exacerbate the depression/suicide and inhibit the adolescent from turning to his or her parents for support and protection. We do not blame the parents for these ruptures. Instead, we help the adolescent to better understand and articulate the deeply felt injustices and disappointment that he or she may not have fully understood and/or expressed to his or her parents. The task ends with empowering and preparing the adolescent to use Task 4 to express these thoughts and feelings in a more mature and regulated manner so that the parents can better listen to these concerns.

Task 3 builds an alliance with the parents (two to four sessions). We initially join with parents by discussing current stressors that are impacting their life: romantic relationships, employment, mental health issues, etc. The therapist offers empathy and support for these challenges and also helps parents see how these stressors might affect their parenting practices. We also explore how the parents' own history of attachment ruptures might impact their parenting. We use both conversations to activate parental caregiving instincts (e.g., their desire to love and protect their child). We leverage this desire to motivate their receptivity to learning new, emotion-focused, attachment-promoting parenting skills (Gottman, Katz, \& Hooven, 1996).

Task 4, the attachment task (one to four sessions), is the central mechanism of the therapy. Here, the adolescent expresses his or her grievances in a more regulated and mature manner. Even if the parents do not fully agree with the adolescent's point of view, most parents feel relieved that their adolescent is speaking directly about conflict rather than acting out, isolating themselves, or engaging in self-harm. As adolescents receive empathy and understanding from their parents, internal working models of parents' availability begin to be revised. This experiential, emotionally charged "corrective attachment experience" challenges their negative expectations of parents and replaces them with a more secure base script about what to expect from parents and other relationships. Several of these conversations maybe needed to build up more confidence in the relationship.

Task 5, the autonomy-promoting task (1-10 sessions), helps family members practice new relational skills, thus consolidating the newly formed secure base. It is one thing to talk openly about past interpersonal disappointments, but another to change interaction patterns in the present and prepare for similar conversations in the future. Thus, the 
therapist shifts attention to promoting the adolescent's autonomy (e.g., school, hobbies, and work) and/or working through other causes of depression/suicide, such as being bullied or divorce. The therapist pushes the adolescent to take developmentally appropriate responsibility for himself or herself while challenging the parents to find the right balance of support and encouragement. Conversations may also focus on identity formation topics, including race, gender, sexual identity, and/or religion.

\section{ABFT RESEARCH}

Although ABFT operationalizes family therapy processes that have relevance for many disorders, most of our research has focused on depression and suicide, specifically for lowincome, minority youth. Depression may be the most common disorder for adolescents in mental health agencies, yet few family interventions models have been tested with this population. Youth suicide is less common, but more severe in its consequence and thus has offered an interesting challenge for intervention development. For both depression and suicide treatment, cognitive-behavioral therapies, with or without medication, have been the primary modalities investigated.

Based on 15 years of research, ABFT is now listed on the National Registry of Empirically Proven Practices (http://www.samhsa.gov/nrepp). This registry catalogs all the treatments that have received some level of empirical evidence and are ready for dissemination. Below, we review these studies including outcome, efficacy, effectiveness, and process research. The majority of clinical trials have been conducted with low-income, minority populations at the Center for Family Intervention Science at Drexel University, formerly at the Children's Hospital of Philadelphia and University of Pennsylvania, Department of Psychiatry. A majority of the process studies have been led by Gary Diamond, both at out center and at Ben Gurion University in Israel.

\section{Clinical Trials Research}

All research starts with small pilot studies. Funding from the National Alliance Research on Schizophrenia and Depression and from the American Foundation for Suicide Prevention (AFSP) supported an open trial of ABFT. The study showed some initial treatment efficacy, but mostly demonstrated that treatment was feasible and acceptable. This work provided pilot data and an initial treatment manual to support funding for the next grant.

\section{First randomized pilot study}

The R34 mechanism supported the full development of a treatment manual and the development and validation of treatment adherence measure. It also allowed us to evaluate feasibility of recruitment, randomization, and other research procedures. Until this study, treatment research for adolescent depression mostly focused medication and cognitive-behavioral therapies. This was the first family therapy study to be conducted with depressed adolescents. It was also one of the few studies of that included a large AfricanAmerican sample (Diamond, Reis, Diamond, Siqueland, \& Isaacs, 2002).

The sample consisted of 32 adolescents (age $M=14.9$ ) between the ages of 13 and 17 who were diagnosed with major depressive disorder (MDD). Of the sample, 78\% were female, $31 \%$ were White, and $69 \%$ were African-American. Approximately $80 \%$ of the sample came from single-parent families, and $69 \%$ lived on less than $\$ 30,000$ a year. Patients were randomly assigned to 12 weeks of ABFT or 6 weeks of a waitlist control condition, an acceptable research design in the 1990s. Those on the waitlist control assignment received weekly 15-minute calls in order to monitor for clinical deterioration. Of the 16 on the 
waitlist, nine of the waitlisted subjects still met eligibility at the end of 6 weeks and were offered treatment.

Of the 16 treatment cases, 13 (81\%) no longer met criteria for MDD at posttreatment, while $7(47 \%)$ of the 15 patients on the waitlist who completed the diagnostic interview no longer met criteria for MDD post-waitlist $(2[1]=4.05, p<.04)$. Although there were not significant differences between the groups on mean Beck Depression Inventory (BDI) scores posttreatment, there was a difference between treatment conditions with regard to the number of adolescents who endorsed posttreatment BDI scores at a nonclinical level $(\mathrm{BDI}<9,2[1]=6.37, p=.01)$. Sixty-two percent of the adolescents treated with ABFT had a BDI of 9 or less compared to $19 \%$ of those on the waitlist condition. At six-month follow-up, $87 \%$ of the treated sample no longer met criteria for MDD and showed significant reductions in depression, anxiety, and negative family functioning (cohesion and conflict). Finally, in terms of treatment retention, $63 \%$ attended nine or more sessions, a high retention rate for a population typically characterized by high levels of early attrition (Mano, Davies, Klein-Tasman, \& Adesso, 2009).

\section{Fully powered randomized control trial}

With a grant from the Centers for Disease Control, we screened and treated suicidal adolescents identified in primary care with the goal of diverting youth from going to the emergency department. Several large primary care sites in our hospital offered to screen and refer patients. This was a study of treatment integration, not collocation. Most suicide studies focus on suicide attempters. In contrast, we focused on adolescents with clinical levels of suicide ideation and depression; a much larger population, but no less troubling to patients, families, and health-care providers. To increase the severity of the sample, patients also had to exhibit elevated depression.

In this study (Diamond et al., 2010), 66 adolescents were randomized to 14 weeks of ABFT or enhanced usual care (EUC). EUC involved assistance in obtaining a therapist in the community, weekly tracking of depression and suicidal ideation, and access to a 24hour crisis line. For an early study of model validation, EUC was an ethical control group without being a fully developed alternative treatment. The sample was $83 \%$ female and adolescents ranged in age between 11 and 18 years $(M=15.20, S D=1.61)$. Of the entire sample, $74 \%$ identified themselves as African-American, $15 \%$ as Caucasian, 3\% as Hispanic/Latino, 3\% as biracial, and 5\% as "other." In addition, 73\% came from single-parent families and $43 \%$ lived on less than $\$ 30,000$ a year. Sixty percent of the adolescents reported having made a suicide attempt in their lifetime.

Compared with EUC, youth treated with ABFT exhibited significantly greater and faster reductions in suicidal ideation during treatment. These differences persisted at followup with a large effect size of .97. ABFT was also associated with greater rates of clinical recovery on suicidal ideation posttreatment. These findings were strengthened by the consistency across self-report and clinician ratings. At the time, this was one of the few studies to demonstrate that a research treatment was more effective than treatment as usual (TAU) for reducing suicidal ideation in adolescents (Ougrin, Tranah, Stahl, Moran, \& Asarnow, 2015). ABFT was even effective with the most severe youth presenting with comorbid anxiety and a history of multiple suicide attempts. A secondary analysis showed that youth with a history of sexual abuse also responded well to treatment (Diamond, Creed, Gillham, Gallop, \& Hamilton, 2012), a finding not supported in several CBT or CBT + medication studies (Asarnow et al., 2009; Barbe, Bridge, Birmaher, Kolko, \& Brent, 2004; Beautrais et al., 1996; Shirk, Kaplinski, \& Gudmundsen, 2009).

Results also indicated that ABFT was associated with greater rates of clinical recovery and treatment retention. At posttreatment, $87 \%$ of patients receiving ABFT reported suicidal ideation scores not only below the clinical cutoff but also in a range consistent or 
below that of a nonclinical sample of similar demographics (Reynolds \& Mazza, 1999). For EUC, only 51\% achieved this level of recovery. Benefits were maintained at follow-up with a strong effect size $(\mathrm{OR}=4.41)$. This study was a breakthrough for ABFT. As one of the only treatments showing success with suicidal youth, it helped put ABFT, and family interventions, on the research map for adolescent depression and suicide. A major limitation of the CDC study was that EUC had a low treatment dose (mean $=2.87$ sessions), while ABFT had a higher dose (mean = 9.71 sessions). Given this difference, we could not be confident that the unique mechanisms of ABFT were accounting for the greater improvement, or if it was an artifact of dose differential.

\section{Second fully powered randomized control trial}

To control for the low dose in the EUC sample, we obtained funding from NIMH to test ABFT against nondirective supportive therapy (NST; Brent \& Kolko, 1991). To control for parent involvement, we added a four-session family psychoeducation component to the NST. To further control for common factors across conditions, we used a crossover design where the same therapists provided both treatments. In this design, patients in both treatments received the same degree of empathy and support, but patients in the ABFT condition also received the active ingredients inherent to the model. To test these purported mechanisms of change, we used the adult attachment interview (George, Kaplan, \& Main, 1985) and a family interaction task as pre- and posttreatment outcome. This allowed us to test whether ABFT changes attachment expectations and improves family interactions, and whether or not these changes mediate long-term outcome. The results of this study will be available within the next 2 years.

\section{Hospital Aftercare Program Evaluation}

Another study focused on patients with an actual suicide attempt. With funding from the AFSP, we tested ABFT as an aftercare model for adolescents coming out of the hospital after a suicide attempt (Diamond, Levy, \& Creed, 2016). Twenty adolescents (80\% female, $65 \%$ African-American), with a mean age of 14.9 years, who had a parent/caregiver willing to participate were recruited from inpatient care following a suicide attempt. Of the parents, $8(40 \%)$ had an income under $\$ 30,000,14(70 \%)$ were single or separated/divorced, and 7 (35\%) had no more than a high school education. Families were randomized to 16 weeks of ABFT or EUC. To enhance continuity of care, we frequently met with inpatient hospital staff (e.g., attended meetings, presented cases, offered clinical trainings for the staff). We also responded promptly (same day) to referral calls, often meeting the family before or at discharge from the hospital.

In terms of feasibility, we met our recruitment goals and collected research/clinical outcome data on $90 \%$ of all randomized patients. Participants receiving ABFT were marginally statistically more satisfied with treatment than those receiving EUC, $t$ $(12)=2.02, p=.07$. Results showed that compared to EUC, ABFT was marginally, but significantly, more effective at preventing future suicide attempts (0\% ABFT, 16.7\% EUC $(1)=3.60, p=.058$; Fisher's exact $p=.206)$, reducing attachment-related avoidance for mothers, $F(1,9)=3.85, p=.08$, and reducing attachment-related anxiety for fathers, $F(1,3)=12.33, p=.04$. In addition, ABFT participants received treatment faster than EUC participants, $t(6)=-2.09, p=.08$. Finally, compared with EUC, ABFT was more effective at reducing attachment-related anxiety for fathers, $F(1,3)=12.33$, $p=.04$. Overall, the results of this study demonstrate that ABFT is both a feasible and acceptable aftercare treatment for youth recently discharged from the hospital after a suicide attempt. 


\section{Effectiveness Research Project}

Our first dissemination study explored the feasibility of training therapists and evaluating depression in a hospital-based, outpatient mental health clinic in Stavanger Norway (Israel \& Diamond, 2013). Research therapists came to the United States for the introductory training and then were subsequently supervised by a certified ABFT supervisor in Norway. Three therapists were trained and credentialed to provide ABFT. Adolescents were referred to the project by central intake. Adolescents were included in the study if they scored a 14 or greater on the Hamilton Depression Rating Scale (HAM-D; Hamilton, 1960) and met criteria for major depression based on the Kiddie-Schedule for Affective Disorders and Schizophrenia (Kaufman et al., 1997).

In total, 20 adolescents were randomly assigned to 12 weeks of ABFT or TAU (ABFT $n=11$, TAU $n=9$ ). A little over $50 \%$ of the sample identified as female and all were between the ages of 13 and $17(M=15.6)$. ABFT patients started treatment within 2 weeks after assignment and TAU families were referred back to central intake. Four of the TAU cases received treatment and five did not. Results showed that there were no statistical differences on the BDI $(z=-.98, p=.32)$ for TAU cases that received treatment and those that did not.

During treatment (12 weeks), youth in ABFT demonstrated significantly greater improvement on the HAM-D (clinician-rated depression), than youth in TAU $(z=-2.05$, $p=.04)$. Analyses at posttreatment revealed that adolescents treated with ABFT had significantly lower ratings on the HAM-D $(z=-2.05, p=.04)$. There was also an eight-point difference between treatment groups on the BDI, but it was not statistically significant $(z=-1.02, p=.23)$. However, the difference between the number of patients who moved from clinical to nonclinical scores on the BDI at posttreatment was greater for adolescents in ABFT at a marginally significant level, $\chi^{2}[d f 1]=2.88, p=.08$.

The primary outcome from the study, however, was the increased knowledge about resolving the implementation challenges. For example, shortly after the study began, senior leadership at the hospital changed. New leadership was less invested in the study, resulting in decreased enthusiasm and support for the study. In addition, two clinical family psychologists left the hospital for other employment during the startup year. The new hospital administrator mandated two other therapists to participate. One therapist was a child, psychodynamic play therapist who usually left parents in the waiting room. These kinds of barriers and our solutions are described in the article by Israel and Diamond (2013). Similar implementation challenges were explored in three recent papers on implementing ABFT in Australia (Diamond, Wagner, \& Levy, 2016), Belgium (Santens, Devacht, Dewulk, Hermans, \& Bosmans, 2016), and Sweden (Ringborg, 2016). They describe both nation-specific and universal challenges and solutions that stem from implementing manualized therapies in new settings.

\section{Adherence Research}

As part of our 2002 study (Diamond et al., 2002), we developed the first ABFT adherence measure (Diamond, Diamond, \& Hogue, 2007). This study examined the fidelity of ABFT for depressed adolescents. Trained observers used the Therapist Behavior Rating Scale (3rd version; Diamond, Hogue, Diamond, \& Siqueland, 1998) to code therapist behaviors in 45 sessions of ABFT and 45 sessions each from two empirically based treatments for adolescent substance abusers: multidimensional family therapy (MDFT) and cognitive-behavioral therapy (CBT). Results indicated that ABFT therapists thoroughly employed essential ABFT interventions, such as focusing on vulnerable affect, highlighting attachment-related themes, and promoting adolescent-parent reattachment through in-session enactments. In accordance with the sequential nature of the treatment, these 
interventions were used more extensively during the early stage of treatment, when there is a greater focus on repairing attachment. ABFT was perfectly discriminable from CBT, with ABFT therapists using more restructuring and repairing attachment interventions and CBT therapists using more signature CBT interventions, such as cognitive monitoring and homework. ABFT was also discriminable from MDFT, with ABFT therapists placing a greater emphasis on repairing attachment. These results helped validate that ABFT can be learned and delivered with fidelity and can be differentiated from other treatments.

Interestingly, our thinking about adherence measures has evolved since this first study. In the TBRS-3, we had one measure with five essential treatment processes, one for each task. However, we do not expect the processes of one task to necessarily show up in other tasks. Therefore, for our next generation of adherence, we developed an adherence measure for each task.

\section{Process Research}

In 2002, we wrote a "manifesto" about how to dismantle and test the proposed mechanisms of ABFT (Diamond \& Diamond, 2002). The ABFT model is built in a unique way that actually isolates and amplifies processes in therapy. Each task has a primary change mechanism and all sessions are associated with a task (e.g., a given task may take 3 weeks). This clinical model helps therapists remain clear about what processes they are focused on at any given time in treatment. In addition, because we video tape each session, we have a vast library of identified tasks, allowing us to design task- or process-specific studies. The common factors are present in all tasks: empathy, support, admiration, acceptance, etc. We are developing coding tools for each task measuring the relative success of that task (e.g., did we accomplish the desired goal of that task?). We will also develop a battery of cross-task coding measures (e.g., emotional processing, and alliance). This will allow us to evaluate if task success is associated with the success of future tasks or with treatment outcome. These kinds of studies also helped us better understand the subtle moment-by-moment processes, decision rules, and pitfalls within each treatment task. Below, we review a few of the studies to demonstrate the kinds of methodologies and findings that characterize this line of research.

\section{Task 1: relational reframe}

One study focused on the relational reframe task (Diamond, Siqueland, \& Diamond, 2003). We sought to understand what processes were involved in shifting the treatment focus from "adolescent as the problem" to "strengthening family relations as the solution." We developed a parent and adolescent pre- and postsession self-report questionnaire to assess changes in clients' views of responsibility for causing and correcting the problems that brought them to treatment. The questionnaire was given to consecutive families at the first treatment session at a community mental health clinic. The depressed adolescents rated conflicts with parents as high in contributing to the problem. In addition, they rated themselves and parents as very responsible and willing to help solve the problem. Interestingly, parents rated themselves as low in contributing to the problem, but capable and willing to help solve the problem. These data highlighted that the adolescent would welcome an interpersonal treatment focus, but that parents needed more "winning over" to a family-based treatment.

Because the families generally rated themselves high on having an interpersonal construction of the problem pretreatment, the measure was not sensitive to postsession change. Therefore, eight parents were interviewed after the first session using a videotape recall method (Elliott, 1984). Among other things, parents approved of the initial siding with adolescents, but expected more equanimity in later sessions. However, parents did 
like the treatment focus. The interviews more clearly elucidated the role that emotions played in the relational reframe process. Eliciting strong, often vulnerable emotions associated with these conflicts helped to challenge negative and often rigid cognitions about problems and about the adolescents themselves (Greenberg \& Safran, 1987). In particular, the greatest clinical leverage occurred when parents came to understand how ruptures in the parent-adolescent relationship contributed to the depression. Understanding the adolescent's desire to be loved helps resuscitate an emotional connection that motivates parental commitment rather than abandonment.

Another study of the relational reframe explored its impact on parents' problem constructions and the reciprocal impact of parents' problem constructions on therapists' use of the relational reframe (Moran, Diamond, \& Diamond, 2005). Looking across five early therapy sessions, we found that relational reframes led parents to construct problems in interpersonal terms in at least two of their six subsequent speech turns. There was partial support for the hypothesis that reframes led to shifts in parents' constructions, from intrapersonal to interpersonal. In good but not poor alliance sessions, parents' interpersonal problem constructions led therapists to use relational reframes.

In another study of the relational reframe, we examined the association between therapist relationship-facilitating and attachment-oriented interventions on one hand and the valence (i.e., positivity-negativity) of parents' attitudes toward their depressed adolescent on the other hand in a sample of 13 sessions of ABFT (Moran \& Diamond, 2008). Parental negativity is associated with the onset and maintenance of adolescent depression. Reducing parental negativity is a primary focus of ABFT. Lag sequential analyses revealed that, in good alliance sessions, relationship-facilitating interventions, such as empathy and positive regard for the parent, were associated with parents' nonnegative attitudes toward their adolescent in the five speech turns subsequent to the intervention. Attachmentoriented interventions, such as relational reframes, addressing core relational themes, and highlighting vulnerable emotions, were also intermittently associated with nonnegative parental attitudes in good alliance sessions. No such effects were evident for the comparison interventions. This study represents a first step in the process of testing specific strategies for reducing parental negativity in family therapy.

\section{Task 2: adolescent alliance}

Currently, we have no completed studies on the adolescent alliance task. Several dissertations on this task, however, are underway.

\section{Task 3: parent alliance}

The parent-therapist alliance is an important factor in determining the effectiveness and efficacy of therapy. Time alone with the parents helps therapists build a strong alliance that helps motivate them to learn emotion-focused parenting skills. A strong alliance with parents is also a robust predictor of treatment retention and outcome (Friedlander, Escudero, Heatherington, \& Diamond, 2011). We have conducted several process studies about the parent alliance task.

In one study that included both Task 2 and Task 3, we sought to understand both the contribution of general therapeutic alliance and specific ABFT alliance processes to outcome (G.S. Diamond et al., 2003). Twenty-three individual sessions with adolescents and 23 individual sessions with parents in the ABFT 2002 outcome study were assessed using a modification of the VTAS (Hartley \& Strupp, 1983) and a new measure with ABFT-specific items. For the adolescents, none of the ratings of VTAS were significantly correlated with depression outcomes, but there was a trend toward associations between alliance and a decrease in parent-adolescent conflict. For the ABFTspecific items, there was a trend for adolescent agreement on individual goals to be 
associated with change in self-reported depression. Adolescent agreement on family goals was not associated with change.

For the parent, overall parent alliance was significantly related to both parents' rating of improvement in adolescent depression and agreement on individual and family goals for treatment. Having a positive view of therapy (or more specifically not having a negative view of therapy) was related to the mother's ability to articulate and agree on individual goals for herself in therapy. We also found that when the therapist initiated the goal of improving family functioning, adolescents reported improvement in both cohesion and perceived attachment to parents. This finding suggests that if the therapist retains his or her focus and the therapeutic framework is meaningful, relevant, and accurate, he or she can succeed in improving family relationships, regardless of whether the adolescent initially agrees to these goals.

Another study explored whether therapists' adherence to five different components of the parent alliance-building (PABT) task was associated with (1) changes in parent-therapist alliance and (2) treatment retention (DeLuca \& Diamond, 2014). It was hypothesized that higher scores on adherence would be associated with higher alliance scores and greater retention in treatment. Results revealed that the intergenerational component of the PABT was associated with changes in parent-therapist alliance $(p=.54)$. The Commitment component was correlated with an improved alliance at the halfway point $(p=.01)$. These results supported the first hypothesis. In support of the second hypothesis, results also revealed that the Preparation component $(p=.024)$ and the Total of all the components $(p=.040)$, for the whole task, were positively correlated with treatment retention.

Finally, in a recent study on Task 3 and Task 4, it was found that the strength of the parent-therapist alliance formed during alliance-building sessions alone with the parents predicted the degree to which parents were able to subsequently employ new and productive parenting skills in subsequent conjoint sessions (Feder \& Diamond, 2016). This research on the processes surrounding parental change, and its impact on adolescent change, has emphasized the importance of engaging parents in this therapy.

\section{Task 4: the attachment task}

A task analysis study about repairing attachment allowed for a more comprehensive development of the clinical model for Task 4 sessions (Stern \& Diamond, unpublished dissertation). Specifically, this exploratory, hypothesis-generating pilot study $(N=3)$ used Task Analysis methods (Rice \& Greenberg, 1984) to help refine parent-adolescent reattachment. The Attachment Task aims to repair long-standing parent-adolescent relational conflicts that may be associated with adolescent depression. As a supplement to the development of an ideal clinical model of the task (Diamond \& Stern, 2003), videotapes of two successful and one unsuccessful Attachment Task episodes were coded with the Structural Analysis of Social Behavior (SASB; Benjamin, 1974). The SASB analysis helped refine and embellish our evolving model of the task, suggesting that the Attachment Task success was associated with high parent affiliation and autonomy. There was also partial support for a phase model of the task, in which successful sessions were associated with a parent disclosure phase that showed both independence and warmth.

\section{Task 5: autonomy promoting}

Currently, we have no process studies looking at Task 5. One area we would like to explore, however, is that of identity development. Many of our patients are from racial or sexual minority communities. We are interested in whether and how parents talk with children about issues of race, discrimination, sexuality, and identity development in 
general. We hope to plan studies that will identify, dismantle, model, and evaluate how these conversations go.

\section{Mechanisms of Change}

One underinvestigated area in family intervention science concerns testing of the purported mechanism of change. To address this in ABFT, Shpigel, Diamond, and Diamond (2012) conducted a secondary analysis with data from our 2010 study. They sought to explore the relationship between changes in parenting behaviors on one hand and changes in adolescent attachment and psychological symptoms on the other hand. More specifically, the study examined whether ABFT was associated with decreases in maternal psychological control and increases in maternal psychological autonomy granting from the first session of therapy (Relational Reframe Task) to the fourth session of therapy (first Attachment Task), and whether such changes were associated with changes in adolescents' attachment schema and psychological symptoms. Eighteen suicidal adolescents and their mothers received 12 weeks of ABFT. Adolescents reported perceived maternal care and control, attachment-related anxiety and avoidance, and depressive symptoms at baseline and 6,12, and 36 weeks. Results indicated that across the first four sessions, maternal psychological control decreased and maternal psychological autonomy granting increased. This increase in autonomy granting was associated with increases in adolescents' perceived parental care from pre- to mid-treatment and decreases in attachmentrelated anxiety and avoidance pre- to posttreatment. Decreases in adolescents' perceived parental control during the treatment were associated with reductions in adolescents' depressive symptoms from pretreatment to 3 months posttreatment. These results suggest that ABFT impacts adolescents' well-being and improves attachment to parents. Further, this study lends support for specific change mechanisms underlying the treatment, particularly in reducing parental control and criticism and increasing parental psychological autonomy granting and care.

\section{Generalizing ABFT to Other Populations}

Although ABFT has been well validated with depressed and suicidal adolescents, this patient population presents with a wide range of clinical challenges. Many of our patients struggle with a history of trauma, eating disorders, substance use, or victimization due to their sexual identity (Levy, Russon, \& Diamond, 2016; Wagner, Diamond, Levy, Russon, \& Litster, 2016; Winley, Ogbaselase, Kodish, Okunrounmu, \& Ewing, 2016). ABFT is flexible enough to incorporate these comorbid conditions. First, attachment is a fairly universal process that underlies the vulnerabilities of many psychiatric disorders. Research has shown that patients with insecure attachment are more at risk for eating disorders, having a history of trauma, and even externalizing disorders such as delinquency and substance use (Illing, Tasca, Balfour, \& Bissada, 2010; Ogle, Rubin, \& Siegler, 2015; Schindler, Thomasius, Sack, Gemeinhardt, \& Küstner, 2007). Second, once attachment ruptures are on the mend and the family can work better as a team, tackling any challenge becomes easier within ABFT. Within Task 5, the manual permits the flexibility to add new treatment goals or even new treatments (with or without a new therapist). Regardless of the content focus, the framework of negotiating or finding the right balance of attachment and autonomy guides the treatment plan. Two specific populations that we have given some empirical attention to are adults with unresolved anger toward a parent (Diamond, Shahar, Sabo, \& Tsvieli, 2016) and suicidal gay, lesbian, and bisexual youth (Diamond, Diamond, et al., 2012). Finally, we did some initial pilot work to adapt ABFT to work with anxious youths in collaboration with our good colleague, Lynne Siqueland, Ph.D. (Siqueland, Rynn, \& Diamond, 2005). 


\section{Young adults with unresolved anger}

One very interesting study compared ABFT with EFT for helping young adults work through unresolved anger toward their parents (Diamond et al., 2016). The study explored whether EFT's two-chair, imagined conversation with one's parents (Greenberg, 2010) had any greater or less effect in facilitating productive processing of primary adaptive emotions and attachment needs than the ABFT in vivo actual conversation with one's parents. Both treatments assumed that productive emotional processing involves moving from global distress or secondary anger into primary maladaptive emotions such as fear or shame, followed by the activation of primary adaptive emotions such as anger, sadness, or compassion. However, in contrast to EFT, productive emotional processing in ABFT is not conceived of as an end in and of itself, but rather as a way to prepare the young adult to communicate their previously unexpressed primary adaptive emotions and unmet attachment needs directly to their parents in conjoint therapy sessions. It is assumed that the acknowledgment or validation directly from the parents may help resolve the anger more than the imaginal resolution during the two-chair technique of EFT. The study also examined whether greater amounts of productive emotional processing predicted more favorable treatment outcomes. Thirty-two young adults $(M$ age $=25.6)$ suffering from unresolved anger toward a parent received 10 weeks of either EFT of ABFT. Self-report measures were collected at baseline, mid-treatment, and posttreatment assessing unresolved anger toward one's target parent; state anger, attachment anxiety, and avoidance in relation to their target parent; and psychological symptoms. These measures were again completed at mid-treatment and immediately posttreatment. Participants were recruited through advertisements posted in two cities stating the "anger must be frequently aroused, have persisted for at least 12 months, and currently interfere with the quality of their relationship with their parent." Participants were told that their parent would have to agree to attend some treatment sessions.

Results showed that while both treatments led to significant and equivalent decreases in anger resolution, state anger, attachment anxiety, and psychological symptoms, only ABFT evidenced a trend toward decreases in attachment avoidance. EFT evidenced significantly more emotional processing. Although the amount of productive emotional processing did not explain the unique decrease in attachment avoidance in ABFT, greater amounts of productive emotional processing predicted greater decreases in psychological symptoms (but not other outcome measures) across both treatments. We had expected that ABFT might have had more emotional processing given the intensity of having difficult conversations with one's parents. However, EFT had more emotional processing. Possibly imagined conversations are idealized and go just as the participant wants and needs. Family conversations, however, are more complex and have to account for the parent's capacity for emotional attunement. Still, this was the first study to examine emotional processing in family therapy and the findings encourage more research.

\section{Lesbian, Gay, and Bisexual Youth}

We have done some preliminary work with Lesbian, Gay, and Bisexual (LGB) suicidal youth. We began this work when we found that nearly $30 \%$ of participants in our 2002 outcome study (Diamond et al., 2010) identified as LGB. We also found, clinically, that ABFT worked well for this subpopulation. To expand this work, Dr. Gary Diamond obtained funding from the AFSP to further adapt ABFT to meet the unique needs of suicidal, openly LGB youth, and their parents (Diamond, Diamond, et al., 2012).

In Phase I of the study, a treatment development team modified ABFT to meet the unique needs of LGB suicidal youth. The treatment was adapted to (1) include more individual time working with parents in order to process their disappointments, pain, anger, 
and fears related to their adolescent's minority sexual identity; (2) address the meaning, implications, and process of acceptance for both parents and adolescents; and (3) heighten parents' awareness of subtle yet potent invalidating responses to their adolescents' sexual identity.

In Phase II, 10 suicidal LGB youth were offered 12 weeks of LGB-sensitive ABFT. Adolescents' report of suicidal ideation, depressive symptoms, and maternal attachmentrelated anxiety and avoidance were gathered at pretreatment, 6 weeks, and 12 weeks (posttreatment). Seven of the 10 families completed a full course of treatment. The study showed that this population can be recruited and successfully treated with a family-based therapy. Preliminary outcome data indicated significant decreases in suicidal ideation, $F$ $(2,14)=38.16, p=.001, d=3.76$; depressive symptoms, $F(2,14)=3.78, p=.05, d=.67$; and maternal attachment-related anxiety, $F(2,8)=10.89, p=.005, d=1.25$; and avoidance, $F(2,8)=4.31, p=.05, d=1.50$. This is the first family-based treatment adapted and tested specifically for suicidal LGB adolescents. Although promising, the results are preliminary and more research on larger samples is warranted.

\section{Anxiety Disorders}

Attachment-based family therapy has also been tested to treat disorders other than depression and suicidality. For example, ABFT was used in a sample of teens diagnosed with anxiety disorders (Diamond, Diamond, et al., 2012; Siqueland et al., 2005). In this study, ABFT and CBT techniques were combined to make a new treatment specifically for anxious adolescents and their families. In Phase I, a manual was developed, therapists were trained, and an open-trial pilot study was conducted to determine feasibility and acceptability. In Phase II, a randomized design was used to determine the feasibility of implementing individual CBT and CBT-ABFT. The majority of patients for this study were recruited at the University of Pennsylvania, from an outpatient program dedicated to treating adolescent anxiety and depressive disorders.

Outcomes showed that CBT-ABFT was successful in addressing adolescent anxiety as assessed by clinically evaluated decreases in self-report of depressive symptoms (Hamilton Anxiety Rating Scale; Hamilton, 1959) and anxiety symptoms (Beck Anxiety Inventory; Beck, Epstein, Brown, \& Steer, 1988). Forty percent of participants in CBT-ABFT no longer met symptoms of depression or anxiety with $80 \%$ continued improvement at followup. There were no significant differences between conditions for psychiatric symptoms; however, those adolescents in the CBT-ABFT condition reported decreases in psychological control, whereas those in the control group reported increases. This could suggest that treatment gains could be further assimilated within the combined treatment, although further research in this area is warranted (Siqueland et al., 2005).

\section{CONCLUSION}

Attachment-based family therapy is an empirically supported treatment designed and developed specifically for repairing attachment ruptures that have damaged trust in the parent-child relationship. ABFT focuses on family factors, such as parental rejection and criticism, low parental warmth, and adolescent-parent conflict; all of which are associated with a host of adolescent problems. The model aims to both help improve individual (adolescents and parents) functioning and interactional processes that create a context for individual development. ABFT has strong empirical support demonstrating the efficacy of the model, as well as preliminary data regarding effectiveness. Additionally, ABFT has a long history of process research that has helped us better understand some of the microchanges within the therapeutic conversation that contribute to treatment success or 
failure. This research has set the foundation for our training program which supports the dissemination of ABFT in eight different countries (www.abfttraining.com or http://www.drexel.edu/familyintervention/abft-training-program/overview/). ABFT is a proven treatment for depressed and/or suicidal youth and their families. Additionally, ABFT seems to have relevance for other presenting problems in a variety of clinical settings.

\section{REFERENCES}

Allen, T. J., Moeller, F. G., Rhoades, H. M., \& Cherek, D. R. (1998). Impulsivity and history of drug dependence. Drug and Alcohol Dependence, 50(2), 137-145. doi:10.1016/S0376-8716(98)00023-4

Asarnow, J. R., Emslie, G., Clarke, G., Wagner, K. D., Spirito, A., Vitiello, B. et al. (2009). Treatment of selective serotonin reuptake inhibitor-resistant depression in adolescents: Predictors and moderators of treatment response. Journal of the American Academy of Child \& Adolescent Psychiatry, 48(3), 330-339. doi:10.1097/ CHI.0b013e3181977476

Barbe, R. P., Bridge, J., Birmaher, B., Kolko, D., \& Brent, D. A. (2004). Suicidality and its relationship to treatment outcome in depressed adolescents. Suicide and Life-Threatening Behavior, 34(1), 44-55. doi:10.1521/ suli.34.1.44.27768.

Beautrais, A. L., Joyce, P. R., Mulder, R. T., Fergusson, D. M., Deavoll, B. J., \& Nightingale, S. K. (1996). Prevalence and comorbidity of mental disorders in persons making serious suicide attempts: A case-control study. American Journal of Psychiatry, 153(8), 1009-1014. doi:10.1176/ajp.153.8.1009.

Beck, A. T., Epstein, N., Brown, G., \& Steer, R. A. (1988). An inventory for measuring clinical anxiety: Psychometric properties. Journal of Consulting and Clinical Psychology, 56(6), 893-897. doi:10.1037/0022006X.56.6.893.

Benjamin, L. S. (1974). Structural analysis of social behavior. Psychological Review, 81(5), 392-425. doi:10.1037/ h0037024.

Boszormenyi-Nagy, I. K., \& Krasner, B. R. (2013). Between give and take: A clinical guide to contextual therapy. New York: Routledge.

Bowlby, J. (1969). Attachment and loss: Attachment (Vol. 1). New York: Basic Books.

Brent, D. A., \& Kolko, D. J. (1991). Supportive relationship treatment manual (NST) (non directive therapy). Pittsburgh, PA: University of Pittsburgh. Unpublished manual.

Cicchetti, D., \& Toth, S. L. (1995). A developmental psychopathology perspective on child abuse and neglect. Journal of the American Academy of Child and Adolescent Psychiatry, 34(5), 541-565. doi:10.1097/00004583199505000-00008.

DeLuca, S., \& Diamond, G. S. (2014). The effects of specific alliance-building techniques on the parent-therapist alliance in Attachment-Based Family Therapy. (Unpublished doctoral dissertation). Philadelphia, PA: Drexel University.

Diamond, G. M. (2014). Attachment-based family therapy interventions. Psychotherapy, 51(1), 15-19. doi:10.1037/a0032689.

Diamond, G. M., Diamond, G. S., \& Hogue, A. (2007). Attachment-based family therapy: Adherence and differentiation. Journal of Marital and Family Therapy, 33(2), 177-191. doi:10.1111/j.1752-0606.2007.00015.x.

Diamond, G. M., Diamond, G. S., Levy, S., Closs, C., Ladipo, T., \& Siqueland, L. (2012). Attachment-based family therapy for suicidal lesbian, gay, and bisexual adolescents: A treatment development study and open trial with preliminary findings. Psychotherapy, 49(1), 62-71. doi:10.1037/a0026247.

Diamond, G. M., Hogue A. T., Diamond G. M., \& Siqueland, L. (1998). Scoring manual for the Therapist Behavior Rating Scale-3rd version. Unpublished manual.

Diamond, G. M., Shahar, B., Sabo, D., \& Tsvieli, N. (2016). Attachment-based family therapy and emotionfocused therapy for unresolved anger: The role of productive emotional processing. Psychotherapy, 53(1), 3444. doi:10.1037/pst0000025.

Diamond, G. S., Creed, T., Gillham, J., Gallop, R., \& Hamilton, J. L. (2012). Sexual trauma history does not moderate treatment outcome in attachment-based family therapy (ABFT) for adolescents with suicide ideation. Journal of Family Psychology, 26(4), 595-605. doi:10.1037/a0028414.

Diamond, G. S., \& Diamond, G. M. (2002). Studying a matrix of change mechanisms: An agenda for family-based process research. In H. A. Liddle, D. A. Santisteban, R. F. Levant, \& J. H. Bray (Eds.), Family psychology: Science-based interventions (pp. 41-66). Washington, DC: American Psychological Association Press. doi:10.1037/10438-000

Diamond, G. S., Diamond, G. M., \& Levy, S. A. (2014). Attachment-based family therapy for depressed adolescents. Washington, DC: American Psychological Association Press.

Diamond, G. S., Levy S., \& Creed, T. (2016). Feasibility, acceptability and outcomes of Attachment-based Family Therapy as an aftercare model for suicidal youth. Manuscript in preparation. 
Diamond, G. S., Reis, B. F., Diamond, G. M., Siqueland, L., \& Isaacs, L. (2002). Attachment-based family therapy for depressed adolescents: A treatment development study. Journal of the American Academy of Child \& Adolescent Psychiatry, 41(10), 1190-1196. doi:10.1097/00004583-200210000-00008.

Diamond, G. S., Siqueland, L., \& Diamond, G. M. (2003). Attachment-based family therapy for depressed adolescents: Programmatic treatment development. Clinical Child and Family Psychology Review, 6(2), 107-127. doi:10.1023/A:1023782510786.

Diamond, G. S., \& Stern, R. S. (2003). Attachment-based family therapy for depressed adolescents: Repairing attachment failures. In S. M. Johnson \& V. E. Whiffen (Eds.), Attachment processes in couple and family therapy (pp. 191-212). New York: Guilford Press.

Diamond, G. S., Wagner, I., Levy, S. A. (2016). Attachment-Based Family Therapy in Australia: Introduction to a Special Issue. Australian \& New Zealand Journal of Family Therapy, 37, 143-153. doi:10.1002/anzf.1148.

Diamond, G. S., Wintersteen, M. B., Brown, G. K., Diamond, G. M., Gallop, R., Shelef, K. et al. (2010). Attachment-based family therapy for adolescents with suicidal ideation: A randomized controlled trial. Journal of the American Academy of Child \& Adolescent Psychiatry, 49(2), 122-131. doi:10.1016/j.jaac.2009.11.002.

Elliott, R. (1984). A discovery-oriented approach to significant events in psychotherapy: Interpersonal process recall and comprehensive process analysis. In L. Rice \& L. Greenberg (Eds.), Patterns of change: Intensive analysis of psychotherapy process (pp. 249-286). New York: Guilford Press.

Erikson, E. H. (1968). Identity: Youth and crisis. New York: W. W. Norton \& Company.

Feder, M. M., \& Diamond, G. M. (2016). Parent-therapist alliance and parent attachment-promoting behaviour in attachment-based family therapy for suicidal and depressed adolescents. Journal of Family Therapy, 38(1), 82-101. doi:10.1111/1467-6427.12078.

Fosha, D. (2000). The transforming power of affect: A model for accelerated change. New York: Basic Books.

Friedlander, M. L., Escudero, V., Heatherington, L., \& Diamond, G. M. (2011). Alliance in couple and family therapy. Psychotherapy, 48(1), 25-33. doi:10.1037/a0022060.

George, C., Kaplan, N., \& Main, M. (1985). The adult attachment interview (AAI). University of California, Berkeley, CA. Unpublished manuscript.

Gottman, J. M., Katz, L. F., \& Hooven, C. (1996). Parental meta-emotion philosophy and the emotional life of families: Theoretical models and preliminary data. Journal of Family Psychology, 10(3), 243-268. doi:10.1037/ 0893-3200.10.3.243.

Greenberg, L. S. (2010). Emotion-focused therapy: A clinical synthesis. Focus: The Journal of Lifelong Learning in Psychiatry, 8(1), 32-42. doi:10.1176/foc.8.1.foc32.

Greenberg, L. S., \& Paivio, S. C. (2003). Working with emotions in psychotherapy (Vol. 13). New York: Guilford Press.

Greenberg, L. S., \& Safran, J. D. (1987). Emotion in psychotherapy: Affect, cognition, and the process of change. New York: Guilford Press.

Hamilton, M. (1959). The assessment of anxiety states by rating. British Journal of Medical Psychology, 32(1), 50-55. doi:10.1111/j.2044-8341.1959.tb00467.x.

Hamilton, M. (1960). A rating scale for depression. Journal of Neurology, Neurosurgery \& Psychiatry, 23, 56-62. doi:10.1136/jnnp.23.1.56.

Hartley, D. E., \& Strupp, H. H. (1983). The therapeutic alliance: Its relationship to outcome in brief psychotherapy. In J. Masling (Ed.), Empirical studies of psychoanalytic theories (pp. 1-38). Hillsdale, NJ: Erlbaum.

Hughes, D. A. (2007). Attachment-focused family therapy. New York: W. W. Norton \& Company.

Illing, V., Tasca, G. A., Balfour, L., \& Bissada, H. (2010). Attachment insecurity predicts eating disorder symptoms and treatment outcomes in a clinical sample of women. Journal of Nervous and Mental Disease, 198(9), 653-659. doi:10.1097/NMD.0b013e3181ef34b2.

Israel, P., \& Diamond, G. S. (2013). Feasibility of attachment based family therapy for depressed clinic-referred Norwegian adolescents. Clinical Child Psychology and Psychiatry, 18(3), 334-350. doi:10.1177/ 1359104512455811.

Johnson, S. M. (2004). The practice of emotionally focused couple therapy: Creating connection (2 $2^{\text {nd }}$ ed.). New York: Brunner-Routledge.

Kaufman, J., Birmaher, B., Brent, D., Rao, U., Flynn, C., Moreci, P. et al. (1997). Schedule for affective disorders and schizophrenia for school-age children-present and lifetime version (K-SADS-PL): Initial reliability and validity. Journal of the American Academy of Child and Adolescent Psychiatry, 36(7), 980-988. doi:10.1097/ 00004583-199707000-00021.

Kobak, R. R., Cassidy, J., Lyons-Ruth, K., \& Ziv, Y. (2006). Attachment and developmental psychopathology. In D. Cicchetti (Ed.), Developmental Psychopathology ( $2^{\text {nd }}$ ed., pp. 333-369). New York: Wiley.

Kobak, R. R., \& Sceery, A. (1988). Attachment in late adolescence: Working models, affect regulation, and representation of self and others. Child Development, 59(1), 135-146. doi:10.2307/1130395.

Levy, S., Russon, J., \& Diamond, G. M. (2016). Attachment-based family therapy for suicidal lesbian, gay and bisexual adolescents: A case study. Australian and New Zealand Journal of Family Therapy, 37(2), 190-206.

Fam. Proc., Vol. x, xxxx, 2016 
Liddle, H. A. (2010). Multidimensional family therapy: A science-based treatment system for adolescent drug abuse. Sucht, 56, 43-50. doi:10.1024/0939-5911/a000011.

Lieberman, A. F. (2004). Child-parent psychotherapy: A relationship-based approach to the treatment of mental health disorders in infancy and early childhood. In A. J. Sameroff, S. C. McDonough, \& K. L. Rosenblum (Eds.), Treating parent-infant relationship problems: Strategies for intervention (pp. 97-122). New York: Guilford Press.

Lynch, M., \& Cicchetti, D. (1991). Patterns of relatedness in maltreated and nonmaltreated children: Connections among multiple representational models. Development and Psychopathology, 3(2), 207-226. doi:10.1017/ S0954579400000080.

Mano, K. E. J., Davies, W. H., Klein-Tasman, B. P., \& Adesso, V. J. (2009). Measurement equivalence of the child behavior checklist among parents of African American adolescents. Journal of Child and Family Studies, 18 (5), 606-620. doi:10.1007/s10826-009-9263-0.

Minuchin, S. (1974). Families \& family therapy. Cambridge, MA: Harvard University Press.

Minuchin, S., \& Fishman, H. C. (1981). Family therapy techniques. Cambridge, MA: Harvard University Press.

Moran, G., \& Diamond, G. M. (2008). Generating nonnegative attitudes among parents of depressed adolescents: The power of empathy, concern, and positive regard. Psychotherapy Research, 18(1), 97-107. doi:10.1080/ 10503300701408325.

Moran, G., Diamond, G. M., \& Diamond, G. S. (2005). The relational reframe and parents' problem constructions in attachment-based family therapy. Psychotherapy Research, 15(3), 226-235. doi:10.1080/ 10503300512331387780.

Ogle, C. M., Rubin, D. C., \& Siegler, I. C. (2015). The relation between insecure attachment and posttraumatic stress: Early life versus adulthood traumas. Psychological Trauma: Theory, Research, Practice, and Policy, 7 (4), 324-332. doi:10.1037/tra0000015.

Ougrin, D., Tranah, T., Stahl, D., Moran, P., \& Asarnow, J. R. (2015). Therapeutic interventions for suicide attempts and self-harm in adolescents: Systematic review and meta-analysis. Journal of the American Academy of Child \& Adolescent Psychiatry, 54(2), 97-107. doi:10.1016/j.jaac.2014.10.009.

Reynolds, W., \& Mazza, J. (1999). Assessment of suicidal ideation in inner-city children and young adolescents: Reliability and validity of the suicidal ideation questionnaire-JR. School Psychology Review, 28(1), 17-30.

Rice, L. N., \& Greenberg, L. S. (1984). The new research paradigm. In L. N. Rice \& L. S. Greenberg (Eds.), Patterns of change: Intensive analysis of psychotherapy process (pp. 7-27). New York: Guilford Press.

Ringborg, M. (2016). Dissemination of attachment-based family therapy in Sweden. Australian and New Zealand Journal of Family Therapy, 37(2), 228-239.

Rosenstein, D. S., \& Horowitz, H. A. (1996). Adolescent attachment and psychopathology. Journal of Consulting and Clinical Psychology, 64(2), 244-253. doi:10.1037/0022-006X.64.2.244.

Santens, T., Devacht, I., Dewulk, S., Hermans, G., \& Bosmans, G. (2016). Attachment-based family therapy between Magritte and Poirot: Dissemination dreams, challenges and solutions in Belgium. Australian and New Zealand Journal of Family Therapy, 37(2), 240-250.

Schindler, A., Thomasius, R., Sack, P. M., Gemeinhardt, B., \& Küstner, U. (2007). Insecure family bases and adolescent drug abuse: A new approach to family patterns of attachment. Attachment \& Human Development, 9 (2), 111-126. doi:10.1080/14616730701349689.

Sheeber, L. B., Hops, H., \& Davis, B. (2001). Family processes in adolescent depression. Clinical Child and Family Psychology Review, 4(1), 19-35. doi:10.1023/A:1009524626436.

Shirk, S. R., Kaplinski, H., \& Gudmundsen, G. (2009). School-based cognitive-behavioral therapy for adolescent depression: A benchmarking study. Journal of Emotional and Behavioral Disorders, 17(2), $106-117$. doi:10.1177/1063426608326202.

Shpigel, M. S., Diamond, G. M., \& Diamond, G. S. (2012). Changes in parenting behaviors, attachment, depressive symptoms, and suicidal ideation in attachment-based family therapy for depressive and suicidal adolescents. Journal of Marital and Family Therapy, 38(s1), 271-283. doi:10.1111/j.1752-0606.2012.00295.x.

Siqueland, L., Rynn, M., \& Diamond, G. S. (2005). Cognitive behavioral and attachment based family therapy for anxious adolescents: Phase I and II studies. Journal of Anxiety Disorders, 19(4), 361-381. doi:10.1016/j.janxdis.2004.04.006.

Solomon, S. D., \& Siegel, D. (2003). Healing trauma: Attachment, mind, body, and brain. New York: W.W. Norton \& Company.

Wagner, I., Diamond, G. S., Levy, S., Russon, J., \& Litster, R. (2016). Attachment-Based Family Therapy as an Adjunct to Family-Based Treatment for Adolescent Anorexia Nervosa. Australian \& New Zealand Journal of Family Therapy, 37, 207-227. doi:10.1002/anzf.1152.

Winley, D., Ogbaselase, F., Kodish, T., Okunrounmu, E., \& Ewing, S. K. (2016). Attachment-Based Family Therapy for teen suicidality complicated by a history sexual trauma. Australian and New Zealand Journal of Family Therapy, 37(2), 177-189.

Young, J. E., Klosko, J. S., \& Weishaar, M. E. (2003). Schema therapy: A practitioner's guide. New York: Guilford Press. 